\title{
Aprendizagem da docência na educação infantil: os saberes de professoras de creches
}

\author{
Learning of teaching in kindergarten: knowledge of \\ daycare teachers
}

\begin{abstract}
Aprendizaje de los maestros en la educación infantil: los conocimientos de las profesoras de la guardería
\end{abstract}

\author{
Monique Aparecida Voltarelli ${ }^{[a]}$, Maria Iolanda Monteiro ${ }^{[b]^{*}}$ \\ [a] Universidade de São Paulo (USP), São Paulo, SP, Brasil \\ [b] Universidade Federal de São Carlos (UFSCar), São Carlos, SP, Brasil
}

\section{Resumo}

O presente trabalho tem por objetivo discutir a respeito dos saberes que os professores detêm para trabalhar em creches. Para desenvolver este estudo, optou-se pela pesquisa de natureza qualitativa, a qual foi realizada em três Centros Municipais de Educação Infantil de uma Rede Municipal de ensino do interior de São Paulo, envolvendo três professoras iniciantes que

MAV: Doutoranda em Educação, e-mail: moniquevoltarelli@yahoo.com.br MIM: Doutora em Educação, e-mail: mimonteiro@ufscar.br 
trabalhavam com crianças de zero a três anos. Realizaram-se observações de campo, registros em diário, análise documental e entrevista semiestruturada. Um ponto de vista em comum, entre as três professoras, refere-se aos saberes advindos da prática profissional e da troca de conhecimentos com professoras mais experientes, que se constituem enquanto as principais fontes de aprendizagem para a docência na educação infantil.

Palavras-chave: Saberes docentes. Aprendizagem da docência. Educação Infantil.

\begin{abstract}
This work discusses about the knowledge that teachers have to work in day care center. In order to develop this study, field observations, diary registers, documental analyses and semi-structured interview were undertaken. A qualitative approach of researching were adopted in three municipal kindergarten educational centers in the countryside of São Paulo, involving three beginner teachers, who work with children from zero to three years old. A common point of view among the three teachers refers to the knowledge acquired in the professional practice by the exchange of knowledge with more experienced teachers, the main source of learning to teach in the nursery care.
\end{abstract}

Keywords: Teaching knowledges. Learning of teaching. Childhood education.

\title{
Resumen
}

Este trabajo discute acerca de los conocimientos que los profesores tienen para trabajar en las guarderías. Para desarrollar este estudio, fue hecho observaciones de campo y registros diarios, análisis de documentos y entrevistas semi-estructuradas. La investigación cualitativa fue adoptada y la pesquisa fue realizada en tres centros municipales de educación infantil de la Red Municipal de São Paulo, con la participación de tres profesoras principiantes que trabajan con niños de cero a tres años. Un punto de vista en común entre las tres maestras, se refiere a los conocimientos que surgen de la práctica profesional y el intercambio de conocimientos con maestras con más experiencias como las principales fuentes de aprendizaje para maestros de la educación infantil.

Palabras clave: Conocimientos para el trabajo docente. Aprendizaje de los maestros. La educación de la niñez. 


\section{Introdução}

A partir de inquietações sobre a prática docente em creches, observa-se uma atuação pautada no assistencialismo com os menores de três anos. Questiona-se, portanto, o fato das professoras passarem a maior parte do tempo realizando atividades relacionadas ao cuidado físico dos pequenos, seja por estarem presas a uma rotina já imposta pela rede, por terem pouco espaço para uma ação pedagógica, por se acomodarem com a sua atuação, por estarem desmotivadas e não serem valorizadas em seu trabalho, por não terem conhecimento de conteúdos a serem desenvolvidos com as crianças de zero a três anos, ou demais possibilidades que possam explicar a falta de uma elaboração e/ou aplicação de um planejamento pedagógico direcionado para o trabalho nas creches.

A aprendizagem da docência e a importância de o professor continuar aprendendo são temáticas que vêm se destacando para a compreensão do desenvolvimento profissional e da formação docente (GARCIA, 1999; MIZUKAMI, 2002; NÓVOA, 1992; TANCREDI, 2009), assim como as questões de cuidar e educar ainda se mostram desconectadas, quando pensamos em práticas pedagógicas na educação infantil (KRAMER, 1999; OLIVEIRA, 2010; ORTIZ, 2007). Este trabalho buscou, então, investigar que saberes o(a) professor(a) tem para trabalhar em creches (TARDIF, 2011), a fim de contribuir para a discussão sobre a formação inicial de professores deste nível de ensino e que tenha, em seu cerne, o cuidar e o educar como princípio de atuação com os pequenos.

\section{Aspectos metodológicos}

Este trabalho é parte do resultado de uma dissertação que possuiu como objetivo geral investigar que saberes o(a) professor(a) tem para trabalhar em creches, a fim de identificar e analisar as concepções manifestas dos(as) professores(as) de creches acerca das funções de educar e cuidar e o papel da creche; os conhecimentos essenciais para o ensino 
nesta faixa etária, além de investigar os saberes destes profissionais, suas fontes de aprendizagens e os ambientes que as favorecem.

As participantes da pesquisa foram três professoras de três diferentes Centros Municipais de Educação Infantil (CEMEI), selecionadas a partir dos seguintes critérios: ser formada em um curso de Licenciatura em Pedagogia; ser efetiva no CEMEI da cidade onde foi realizada a pesquisa; ser iniciante na educação infantil com no máximo cinco anos de profissão. A metodologia adotada para o desenvolvimento deste estudo foi uma pesquisa de natureza qualitativa. Após a aprovação do Comitê de Ética em Pesquisa em Seres Humanos da Universidade Federal de São Carlos (Parecer n. 118/2012) e da Secretaria Municipal de Educação do município, aliados à aceitação das CEMEIs e das professoras em participar da pesquisa, foram selecionadas uma professora por CEMEI de três bairros distintos.

Em cada instituição foi entrevistada uma professora que se compõe da seguinte forma: na CEMEI mais próxima do centro da cidade entrevistou-se uma professora da fase I (trabalha com o berçário, com crianças de quatro meses a um ano); em outra CEMEI, não tão próxima do centro, uma professora da fase II (com crianças de um para dois anos); e a outra instituição localizada em um bairro bem distante do centro, a professora da fase III (com crianças de dois para três anos). Perpassando, assim, a atuação profissional de zero a três anos, período este que a pesquisa se propôs a investigar.

A pesquisa em campo foi realizada em quatro meses, contando com a observação e entrevistas semiestruturadas com as professoras. Também houve análises de documentos das instituições e do município, desde diários de classe até o Estatuto da Educação do município pesquisado. O estudo preocupou-se em selecionar professoras iniciantes que estão aprendendo a docência na educação infantil para saber como elas vão se constituindo neste processo diante do cenário imposto pelo município. As observações foram realizadas por cerca de um pouco mais de um mês na sala de cada professora, onde as atividades eram registradas em um 
diário de campo que possibilitou, por meio das entrevistas semiestruturadas, a formação de quatro categorias de análise de dados.

\section{A Educação Infantil}

Com os avanços da história sobre o conceito de infância e a partir das novas mudanças das políticas educacionais e sociais, pode-se perceber a creche como uma instituição ampla e repleta de significações que vão nortear o trabalho do professor e o atendimento das crianças de zero a três anos. A partir do final do século XX e início do século XXI, as creches passam a ser pensadas como uma instituição educacional preocupada com o respeito às diferenças, com o cuidado coletivo e com a pluralidade cultural centrada na criança. É importante destacar que, no decorrer da história, a formação de professores que trabalham com educação infantil sempre foi muito carente, uma vez que esta área de ensino não exigia formação de ensino superior, sendo associada a conhecimentos maternos e de cuidado com a criança, predominando o trabalho feminino, mesmo sem instrução adequada para o atendimento delas.

Sobre a formação dos professores, Ortiz (2007, p. 10) vem destacar a preocupação da falta da valorização do trabalho do profissional da creche e a possível ausência de uma proposta pedagógica para as crianças menores de três anos, reduzindo a prática do professor apenas ao cuidado físico da criança. Segundo Abramowicz e Wajskop (1999, p. 6), a concepção que norteou a prática educacional das creches ao longo dos anos conservou uma relação direta com a concepção de infância presente e utilizada em cada época histórica e com a questão das transformações e posições assumidas pelas diferentes classes sociais as quais se destinavam a instituição.

Mantovani (1999, p. 85) aponta para a necessidade de os professores obterem conhecimentos sociológicos, a fim de que compreendam o contexto em que a criança está inserida para, a partir deste entendimento, passar a vê-la enquanto sujeito histórico e ativo em sua realidade. 
De acordo com o que se tem pensado para o atendimento das crianças, acredita-se que a construção de uma pedagogia para infância seja um novo caminho a ser seguido, de forma que valorize as culturas infantis, sua criatividade seja potencializada e que se reconheça a família como parceira deste processo.

Outra fala que consideramos importante é de Cerisara (2004, p. 11), quando afirma que as crianças, desde muito pequenas, possuem uma história e fazem cultura. Para discorrer sobre a pedagogia da infância, pensa-se a criança enquanto protagonista. Ao tomar como ponto de partida a criança enquanto sujeito de direitos, garantidos por leis e diretrizes nacionais, as quais têm se preocupado em garantir o atendimento adequado em uma instituição educativa não apenas assistencial, mas promotora de educação e cuidado voltado para o desenvolvimento integral da criança, remonta-se o cenário e caráter complexos abarcados pelo tema. Estes fatos remetem a diversos aspectos e especificidades que envolvem a educação infantil e o que se tem proposto para trabalhar com as crianças menores de cinco anos.

Oliveira e Tebet (2010, p. 48) afirmam que é a visão "autocêntrica" que atrapalha o trabalho do professor em perceber a criança enquanto ator social, como um ser que interage no meio em que vive, que produz cultura e que busca atrelar sentido as coisas à sua volta. Maneira de ver o mundo que ainda está muito distante da percepção de um adulto e, sendo assim, reforça-se a necessidade de preservar tal singularidade. Para este entendimento da criança, estudos têm sido desenvolvidos na perspectiva da Sociologia da Infância, a qual visa "construir uma ideia de crianças e de infâncias de maneira positiva, valorizando suas singularidades, linguagens, culturas e estéticas" (OLIVEIRA; TEBET, 2010, p. 44). O que a Sociologia da Infância tem feito é contribuir com pontos centrais na elaboração do que vem sendo chamado de Pedagogia da Infância (CERISARA, 2004), uma vez que é preciso legitimar a voz das crianças e considerá-las como arquitetas destas novas práticas pedagógicas.

Neste aspecto, Faria e Finco (2011) defendem a necessidade de rever as formas como a educação tem sido trabalhada nestas idades, 
de forma a "superar aquela educação reprodutora que didatiza o lúdico, patologiza a infância e reduz a educação ao ensino" (p. xvi), para promover uma educação que valorize o convívio com as diferenças, que priorize as expressões infantis, que agregue as famílias nas creches, optando por considerar o ato de brincar como um "favorecedor de descobertas" (FARIA; FINCO, 2011).

\section{Saberes docentes no universo da creche}

Para realizar a discussão e compreender a aprendizagem da docência na educação infantil, recorreu-se à abordagem dos quatro eixos de análises de dados, que envolveram: a concepção de creche para as professoras; as ações de educar e cuidar; os conteúdos ensinados para as crianças de zero a três anos; e as aprendizagens da docência na creche.

De acordo com a pesquisa em relação às concepções das professoras sobre a creche, ficou evidente, na fala das professoras da fase II e III, que este é como um lugar para os responsáveis deixarem as crianças, na qual a prioridade vem sendo o cuidar. Mesmo acreditando no fato de que a creche é uma instituição destinada para o desenvolvimento da criança, as professoras reforçaram a questão do assistencialismo e da visão de creche enquanto um "depósito de crianças". Já a professora da fase I, tinha a concepção de creche enquanto um espaço público destinado às crianças e pensado para a sua vivência e socialização.

A professora da fase III comentava em sala de aula, conforme observado em campo, a questão assistencial da creche, dizendo que ela trabalhava sozinha, com uma grande quantidade de crianças e ainda tinha que ajudar todo mundo se trocar, escovar os dentes e arrumar o cabelo das meninas para que pudessem ir embora sem as mães reclamarem. A professora da fase II destacava que sua concepção de creche era idealizada, se referindo a uma instituição na qual se priorizasse o desenvolvimento da criança, com regras a serem respeitadas por todos quanto ao seu funcionamento, como um espaço voltado para a educação. 
Os estudos de Faria (1999), Kuhlmann Jr. (2000), Kramer (2011) e Oliveira (2010) têm discutido a concepção de creche enquanto assistência às famílias trabalhadoras e que, historicamente, foi priorizando o cuidado físico em detrimento do educar, o que envolveu um caráter compensatório por parte das políticas públicas que se destinaram a suprir o atendimento emergencial dos pequenos para que os pais pudessem ter um lugar seguro para deixar os filhos enquanto estivessem trabalhando.

Devido a esta situação, a infância ficou em segundo plano e a creche se tornou uma instituição "substituta, limitando-se a desenvolver atividades que restringem o olhar da criança a uma esfera muito imediata" (OLIVEIRA, 2010, p. 43). Ressalta-se a importância de se discutir essa noção de creche, que nos últimos anos vem lutando para mudar o viés assistencialista, sendo incluída pela legislação nacional enquanto parte da educação básica e que requer profissionais com formação para atender o público infantil.

Trabalhar com crianças menores de cinco anos, é uma atividade complexa (ABRAMOWICZ; MORUZZI, 2010), e que demonstra cada vez mais a necessidade de se garantir um profissional em nível superior com uma formação mais ampla e específica para dar conta das nuances deste nível de ensino. O professor, ao se tornar consciente de suas concepções, pode facilitar o desenvolvimento e a organização de sua prática pedagógica. Ao identificar como o docente percebe a realidade em que vive, passa a se ter elementos para refletir sua postura dentro de sala e elencar fatores para a mudança. Garcia (1999, p. 113) afirma que a iniciação à docência é um período em que os profissionais fazem a transição de estudantes para professores, bem como ocorrem grandes tensões e aprendizagens intensas nos contextos mais variados de ensino. Assim, a atitude aberta para a análise reflexiva de sua própria prática e dos demais colegas de trabalho poderia contribuir com o desenvolvimento profissional, aprimorando a aprendizagem na docência.

Em relação às ações de educar e cuidar, observa-se que são, historicamente, discutidas como essenciais para atuação do profissional da educação infantil, mas que ainda hoje buscam por um equilíbrio nas 
instituições que atendem os pequenos. Neste eixo, abordaram-se como as professoras de fase I, II e III concebem estas funções, e como são desempenhadas na prática diária destas profissionais, a fim de verificar como ocorria a atuação destas professoras nas creches, uma vez que o papel do profissional de educação infantil está atrelado a estas duas ações.

Ao perguntar para as professoras como concebiam as funções de educar e cuidar, obteve-se respostas parecidas no sentido de pensar que as mesmas caminham juntas. Entretanto, obteve-se respostas distintas ao se refletir sobre tais funções na prática de cada uma, principalmente no que se refere ao atendimento das diferentes faixas etárias da creche, como se pode evidenciar nos relatos abaixo:

Eu acho que enquanto as crianças que são pequenas não têm condições de ter cuidados pessoais sozinhas, é obrigação de o adulto fazer isso, e ai aquela concepção de que toda forma de cuidado ela traz uma forma de educação... (Fala da professora da fase I, durante a entrevista, 31/10/11).

[...] não tem como cuidar sem educar e vice-versa, principalmente com as crianças pequeninhas, porque você está cuidando, está trocando fraldas, quando está lavando a mãozinha, está ensinando higiene, está ensinando eles a terem autonomia, então no cuidar a gente também está educando né. (Fala da professora da fase II, durante a entrevista, 19/09/11).

A professora da fase II acreditava que a criança aprende muito por meio do exemplo, que o professor precisava estar sempre se policiando, para não pedir para as crianças uma coisa e fazer outra, conforme comenta na entrevista:

A gente fala para a criança não gritar, gritando, por exemplo, então a gente às vezes tem que tomar alguns cuidados, eu acho que exemplo é tudo. Nas atividades diárias, nas musiquinhas, o carinho, o cuidado [...] (Fala da professora da fase II, durante a entrevista, 19/09/11). 
As três professoras tinham clareza que as suas funções enquanto profissionais da creche deveriam indissociar o cuidar do educar. Em concordância com os relatos da professora da fase III (anotações no diário de campo), quando dizia que, às vezes, o cuidar se tornava prioridade, com as demais professoras não foi diferente.

De acordo com os registros no diário de campo, nem sempre as professoras conseguiam promover grandes interações educativas em todos os momentos de trocas e de banho, pois elas tinham horários para cumprir e uma grande quantidade de crianças para atender, não conseguindo realmente ensinar em todos os momentos que estavam cuidando. Entretanto, negar essa ação por parte das professoras também não seria verdadeiro, pois, por muitos momentos, também foi possível notar, durante as visitas a campo, o quanto as professoras educam nos momentos em que elas não estão com esta intenção, em momentos em que não estavam realizando as atividades consideradas por elas "pedagógicas", mas que pelo exemplo, da fala, do contato, das ações, durante o dia com a criança, estavam educando (mesmo sem perceber).

Oliveira (2010, p. 47) aponta a necessidade dos profissionais da educação infantil na valorização do cuidar, já que é no contato e na interação com a criança, que se ensina o respeito, o afeto, o cuidado, a conquista da autonomia, enfim, uma série de informações e conhecimentos que serão aprendidos pelas crianças e que caminham ao lado do trabalho educativo desenvolvido nas creches e pré-escolas. A instituição de educação infantil é um espaço caracterizado pela integração da ação de cuidar e educar, sendo que Kuhlmann Jr. (2000, p. 64) afirma ser imprescindível tomar a criança como ponto de partida para se pensar em propostas pedagógicas na creche.

No que concerne aos conteúdos ensinados para as crianças de zero a três anos, o propósito foi o de investigar o que as professoras entendem sobre o trabalho que desenvolvem com os pequenos e discutir questões a respeito dos conhecimentos essenciais, a partir das perspectivas das professoras da fase I, II e III, para trabalhar com as crianças de zero a três anos. Ao questionar as professoras sobre essa questão (durante 
a entrevista), percebeu-se que a preocupação da professora da fase I estava voltada especialmente na forma como se ensina as crianças, nas estratégias utilizadas e na adaptação dos conteúdos para desenvolver um trabalho com os bebês. Em suma, a preocupação da professora não era com o conteúdo em si, mas com a forma que tal conteúdo seria apresentado para as crianças, no sentido de ser funcional e de ter um significado para elas, descobrindo em uma ação conjunta novas formas de trabalhar.

A professora da fase II enfatizou (durante a entrevista) a relevância da socialização das crianças nas três fases da creche, uma vez que o aprendizado sobre esperar, ter tolerância, ter paciência, comunicação, dividir com o outro, estimular o desenvolvimento, psicomotricidade, a autonomia, a oralidade, trabalhar com texturas, sensações, musicalização, contação de histórias, são alguns elementos fundamentais para se trabalhar na creche, desde bebês até os três anos de idade.

Já a professora da fase III acreditava na importância de se desenvolver atividades relacionadas com o conhecimento e o cuidado do próprio corpo, questões de higienização, alimentação, postura e comportamento para realizar estas atividades em sociedade, são essenciais para ser trabalhado em creche (conforme relatado na entrevista). A professora acreditava que através do lúdico poderia conseguir ganhos com a criança no que tange aos itens citados acima, e que precisaria perpassar por todo o processo de desenvolvimento da criança.

Sobre esse aspecto, pode-se observar ainda na fala das três professoras a necessidade de se compreender o desenvolvimento infantil para trabalhar com as crianças menores de três anos. Todas consideram importante o fato de se entender o processo de desenvolvimento das crianças com o objetivo de identificar as maiores necessidades na faixa etária que os pequenos se encontram e perceber os limites de cada idade para, a partir deste ponto, pensar em atividades que estimulem, potencializem e favoreçam o ganho de autonomia da criança, realizando atividades básicas coerentes com as conquistas possíveis dentro de cada faixa etária.

Quando o professor iniciante chega à instituição de educação infantil tem uma grande dificuldade em associar a teoria que aprendeu nas 
atividades práticas a serem desenvolvidas na creche. Durante as observações, foi possível constatar a necessidade das três professoras pesquisadas em consultar a literatura para poder pensar em atividades práticas que estimulem o desenvolvimento das crianças, o que certamente é um saber essencial para trabalhar com os pequenos.

Percebe-se, de acordo com Tardif (2011, p. 63), que o papel dos livros e demais obras literárias é o de um importante elemento das fontes de aprendizagem das professoras, visto que adquirem saberes para sua prática pautando-se no uso de livros, obras literárias e demais materiais didáticos. As professoras, portanto, elencaram o desenvolvimento infantil, a criatividade, o ensino de regras, a socialização e o trabalho apoiado na psicologia para a educação infantil, como conhecimentos essenciais para se trabalhar na creche.

Importante destacar que em relação aos conteúdos trabalhados, as professoras acreditavam que, conforme a criança vai crescendo, é possível se trabalhar as mesmas atividades, mas aumentando a exigência, com o intento de melhorar a coordenação motora das crianças para realizar o que lhes é proposto. Assim, os conteúdos irão variar no grau e na intencionalidade das atividades realizadas com as crianças, tendo ciência de que as exigências precisam estar coerentes com a faixa etária.

O eixo sobre as aprendizagens da docência na creche teve como finalidade investigar como as professoras pesquisadas aprendem a serem professoras de creche e o que contribui para a aprendizagem da docência nesta fase de início de carreira que elas se encontram. As questões sobre a aprendizagem da docência utilizadas para análise se relacionam com a posição das professoras pesquisadas e retratam alguns aspectos que favorecem essa formação. De acordo com o que foi vivenciado pelas professoras e que foi dialogado com as contribuições dos autores da área, pode-se pensar em contextos formativos e desenvolvimento profissional docente.

Por meio das entrevistas e da investigação documental das grades curriculares dos cursos de graduação das professoras, visualizou-se que elas possuem uma boa formação e todas se mostraram preocupadas em continuar os estudos para aprimorar a prática em sala de aula. 
Comentaram sobre o fato de o curso de Licenciatura em Pedagogia não preparar o docente para atuar com crianças menores de três anos, bem como as disciplinas relacionadas à educação infantil, dificilmente, se atentarem para essa faixa etária. Garcia (1999, p. 25) assevera que é na formação inicial que o professor adquire conhecimentos pedagógicos e aprimora seu embasamento para suas futuras práticas de ensino, e que essa formação se constitui apenas como um primeiro processo para a aprendizagem docente.

As professoras ressaltavam que todos os aspectos da vida contribuem e influenciam no desenvolvimento profissional docente, pois como diziam, durante a entrevista, não há como separar o profissional do pessoal, ou seja, não é possível isolar a formação das experiências vividas enquanto professoras e enquanto alunas. Os próprios exemplos familiares que tiveram, impactam no modo como pensam, como elaboram e como se tornam docentes. Quando perguntamos as professoras durante a entrevista como elas aprenderam a serem professoras de crianças de zero a três anos, elas reforçaram a questão da própria experiência prática, conforme visualiza-se abaixo:

Eu acho que inicialmente na universidade mesmo, na faculdade, matérias teóricas e tal, mas o dia a dia assim foi na prática mesmo, meu primeiro ano, numa fase dois eu trabalhei com duas professoras muito experientes, muito dedicadas, muito cheia de ideias, então foi muito bacana. (Fala da professora da fase I durante a entrevista, 30/10/11).

Olha foi na prática mesmo, foi quando eu entrei na creche em 2001, porque nem fralda eu sabia trocar (risos) então foi pedindo ajuda para as outras professoras, da diretora às vezes eu pedia ajuda também, eu não tinha muita prática, aliás eu não tinha prática nenhuma né. (Fala da professora da fase II durante a entrevista, 19/09/11).

Eu acho que mais na prática, pegando informações de colegas de serviço, procurando na internet, mais do que na faculdade. (Fala da professora da fase III, durante a entrevista, 09/12/11). 
O registro das manifestações das docentes articula com o posicionamento teórico de Tardif (2011, p. 14), pois ressalta que é no contexto da socialização profissional que o professor incorpora saberes que se referem à função da profissão e que são adquiridos e ajustados conforme o docente realiza o seu trabalho, sendo que esse processo ocorre por todo o sistema de desenvolvimento profissional e assim vai interiorizando "por meio de regras da ação que se tornam parte integrante de sua 'consciência prática”' (p. 14). O autor ainda destaca que o saber do professor possui características próprias do trabalho que é desenvolvido diariamente, pois o mesmo é construído e aperfeiçoado durante a prática docente.

A fonte de aprendizagem da docência deriva de vários fatores, que provém de diferentes fontes e que possuem um significado diferente para cada uma delas. Cada experiência possuiu um impacto diferente na aprendizagem docente de cada professora, o que faz com que elas atribuam significados diferentes para cada ação também. A partir da entrevista, pode-se perceber que as professoras possuem de três a quatro anos de experiência docente e estão no que Tardif (2011, p. 50) coloca como início de carreira, ao considerar as práticas com até cinco anos na profissão. $\mathrm{O}$ autor estabelece que nesta fase o processo de aprendizagem da docência é rápido e se constituiu como uma experiência fundamental para sua atuação docente, uma vez que "mergulhados na prática, tendo que aprender fazendo, os professores devem provar a si próprios e aos outros que são capazes de ensinar" (p. 51), o que posteriormente fundamentará também a personalidade profissional dos professores.

A professora da fase I, da mesma forma que as professoras da fase II e III, comentaram que, além da formação universitária, o contato com boas leituras e o incentivo familiar influencia o desenvolvimento profissional delas, por oferecerem um apoio e uma base que elas podem recorrer sempre que precisar. Tardif (2011, p. 63) ressalta que a família se apresenta como uma importante fonte de aprendizagem para os professores, por influenciar na postura profissional, diante do ensino, envolvendo questões de crenças, valores, regras que também orientam a prática docente. 
A aprendizagem da docência se torna um processo contínuo e que ocorre por toda a carreira profissional do professor, que se inicia antes mesmo dos cursos de licenciatura, pois enquanto aluno aprende-se a ser docente por meio da observação realizada, durante toda a vida escolar. Assim, a formação inicial vai refinar esse olhar do professor e fornecer elementos teóricos que o farão refletir e adquirir saberes para a docência profissional. Os saberes profissionais serão constituídos através de tentativas e erros (GARCIA, 1999), os quais serão vivenciados pelo professor iniciante por meio do trabalho realizado cotidianamente com as crianças.

Conforme vai ganhando experiência profissional, o docente vai identificando melhor as suas carências formativas, elencando elementos que fazem falta para sua prática profissional. De acordo com o que disseram as professoras na entrevista, a formação inicial não deu conta para o trabalho nas creches, reforçando o que se tem defendido nesse trabalho: a necessidade de uma formação que se atente para a infância e para a educação infantil.

A sociologia da infância, bem como a intenção de se construir uma pedagogia para infância, pode ser ressaltada neste aspecto do "olhar as crianças", uma vez que a creche é uma possiblidade de convívio com as diferenças, pois é um ambiente permeado pela heterogeneidade.

No decorrer da iniciação docente, o fato das professoras se unirem para construir um ambiente de aprendizagem coletivo e fazer-se entender os processos de aprimoração profissional, podem contribuir com a criação de uma cultura profissional (NÓVOA, 2009) de aprendizagem no ambiente de trabalho e colaborar para que os iniciantes e os experientes fortaleçam sua autonomia docente.

No mundo destas interações orientadas por contextos docentes de aprendizagens coletivas pode-se fortalecer a compreensão de que sujeitos e contextos fazem parte do âmbito cultural (OLIVEIRAFORMOSINHO, 2007). Assim, poderia se pensar no trabalho com os processos de construção de uma pedagogia da infância, na qual a participação, a observação das crianças, a escuta e a negociação criasse uma cultura 
de relacionamento com os pequenos, a fim de promover um trabalho que tomasse a criança como objeto principal.

A aprendizagem através da troca entre os pares (GARCIA, 1999; MIZUKAMI, 2002; NÓVOA, 1995; TANCREDI, 2009) vem sendo considerada uma grande fonte de aprendizagem da docência por permitir que os profissionais compartilhem saberes e conhecimentos da prática, de forma a "ouvir e compreender, a analisar sem criticar, a apoiar sem desmerecer" (TANCREDI, 2009, p. 26). Essa troca faz com que o professor aprenda a refletir sobre o que precisa manter e o que mudar em sua atuação profissional, contribuindo para o desenvolvimento do docente diante das situações imprevistas do cotidiano escolar, auxiliando-o a tomar decisões rápidas para atender as especificidades e a complexidade do ato de ensinar.

\section{Considerações finais}

As análises apontam que as professoras sabem o que trabalhar com as crianças e sabem onde procurar atividades para realizar com elas. As professoras se mostram comprometidas com a profissão e compreendem em que direção realizam seus trabalhos, o que buscam desenvolver com as crianças e a importância de se concretizar um trabalho educativo ao lado do cuidado necessário aos menores de três anos. As profissionais afirmaram ainda que as atividades realizadas na creche não são diferentes em relação a conteúdos, mas sim ao grau de dificuldade e de intencionalidade que acompanham as faixas etárias das crianças na creche e que as exigências devem estar de acordo com o desenvolvimento infantil e com as especificidades da idade das crianças.

As professoras ressaltam a importância do trabalho colaborativo e da necessidade de se resgatar o planejamento com a participação de todas as professoras da sala, bem como troca de experiências com as colegas de trabalho, uma vez que estes se apresentam como uma fonte de 
aprendizagem para a docência e influencia o trabalho de todas as professoras iniciantes envolvidas nesta pesquisa.

Pensar na formação de professores requer considerar aspectos como o "desenvolvimento pessoal (produzir a vida do professor), com o desenvolvimento profissional (produzir a profissão docente) e com o desenvolvimento organizacional (produzir a escola)" (NÓVOA, 1992, p. 15). Em outras palavras, para produzir a escola e a profissão docente necessita-se de uma orientação e uma coordenação a fim de que se suceda a formação dos profissionais que nela estão inseridos, uma vez que se percebeu uma ausência de investimentos públicos para este tipo de formação. Sugere-se, entretanto, a possibilidade de as políticas públicas investir na aprendizagem docente dentro do ambiente de trabalho, utilizando os saberes que os professores já possuem e para enriquecer as práticas docentes através de troca, e reflexão durante processo de formação na instituição escolar.

As professoras ressaltaram na entrevista algumas fontes que embasam suas práticas profissionais e contribuem com a aprendizagem da docência. Disseram que quando sentem dificuldades ou procuram formas de melhorar a sua atuação profissional, recorrem a periódicos, a teorias, internet, aos saberes de professoras mais experientes, a própria experiência familiar, bem como a própria experiência em sala de aula, usando da criatividade e adaptando, conforme a vivência que possuem, as atividades para as crianças.

Os saberes docentes, construídos pelas professoras, advêm de diversas fontes de aprendizagem, conforme já nos afirmou Tardif (2011, p. 38), e se constituem de saberes advindos da formação inicial, da formação continuada, de saberes advindos das experiências enquanto alunas, saberes provenientes de livros e programas curriculares e de saberes adquiridos pela experiência.

As três professoras ressaltaram que os saberes advindos da prática profissional e da troca de conhecimentos com professoras mais experientes, se constituem como as principais fontes de aprendizagem, a partir da ótica delas, para a aprendizagem da docência para o trabalho na 
creche. O gostar de crianças e ter paciência não garantem o trabalho pedagógico com os pequenos. Para trabalhar com os bebês e com as crianças de dois e três anos, as professoras necessitam construir uma base de conhecimentos e vivenciar demais situações de ensino que sejam significativas para a aprendizagem docente na creche.

Apontou-se a sociologia da infância como possibilidade formativa a ser integrada nos cursos de formação, com a intenção de se pensar em uma pedagogia da/e para a infância, de modo que o professor possa refletir sobre elementos a serem considerados no trabalho com os pequenos, de forma lúdica, não escolarizante, não discriminatória e que potencialize as aprendizagens infantis. A diversidade e a riqueza de possibilidades de trabalho traduzem a complexidade da docência para atuar com os menores de três anos, pois determinam as práticas pedagógicas de acordo com a imagem, com a compreensão, com a conceitualização que os professores possuem a respeito da criança, da infância e das creches.

\section{Referências}

ABRAMOWICZ, A; MORUZZI, A. B. (Orgs.). O plural da infância: aportes da Sociologia. São Carlos: EdUFSCar, 2010.

ABRAMOWICZ, A.; WAJSKOP, G. Educação Infantil: creches - atividades para crianças de zero a seis anos. São Paulo: Moderna, 1999.

CERISARA, A. B. Por uma pedagogia da educação infantil: desafios e perspectivas para as professoras. In: SECRETARIA MUNICIPAL DE EDUCAÇÃO - SP. Caderno Temático de Formação II - Educação Infantil: construindo a Pedagogia da Infância no município de São Paulo. São Paulo: SME-SP, 2004. p. 7-16.

FARIA, A. L. G. Educação pré-escolar e cultura. Campinas: Editora da Unicamp; São Paulo: Cortez Editora, 1999.

FARIA, A. L. G.; FINCO, D. (Orgs.). Sociologia da Infância no Brasil. Campinas: Editora Autores Associados, 2011. 
GARCIA, C. M. Formação de professores: por uma mudança significativa. Porto: Porto Editora, 1999.

KRAMER, S. Formação de profissionais de educação infantil: questões e tensões. In: MACHADO, M. L. A. Encontros e desencontros em educação infantil. São Paulo: Cortez Editora, 2011. p. 117-132.

KRAMER, S. O papel social da educação infantil. Brasília: Ministério das Relações Exteriores, 1999.

KUHLMANN JR., M. Educação Infantil e currículo. In: FARIA, A. L. G.; PALHARES, M.S. (Orgs.). Educação infantil pós-LDB: rumos e desafios. Campinas: Editora Autores Associados/Unicamp; São Carlos: EdUFSCar; Florianópolis: Editora da UFSC, 2000. p. 51-66.

MANTOVANI, S.; PERANI, R. M. Uma profissão a ser inventada: o educador da primeira infância. Pro-posições, v. 10, n. 28, p. 75-98, mar. 1999.

MIZUKAMI, M. G. N. et al. Escola e aprendizagem da docência: processos de investigação e formação. São Carlos: EdUFSCar, 2002.

NÓVOA, A. As organizações escolares em análise. Lisboa: Dom Quixote, 1995.

NÓVOA, A. Formação de professores e profissão docente. In: NÓVOA, A. (Org.). Os professores e sua formação. Lisboa: Dom Quixote, 1992. p. 13-33.

NÓVOA, A. Professores: imagens do futuro presente. Lisboa: EDUCA, 2009.

OLIVEIRA, F.; TEBET, G. G. C. Cultura da infância: brincar, desenho e pensamento. In: ABRAMOWICZ, A.; MORUZZI, A. B. (Orgs.). O plural da infância. São Carlos: EdUFSCar, 2010. p. 39-54.

OliVEIRA-FORMOSINHO, J.; KISHIMOTO, T. M.; PINAZZA, M. A. (Orgs.). Pedagogias(s) da infância: dialogando com o passado - construindo o futuro. Porto Alegre: Artmed, 2007.

OLIVEIRA, Z. M. R. Educação infantil: fundamentos e métodos. São Paulo: Cortez Editora, 2010. 
ORTIZ, C. O papel do professor de crianças pequenas. Pátio - Educação Infantil, v. 5, n. 13, p. 10-13, mar. 2007.

TANGREDI, R. P. Aprendizagem da docência e profissionalização: elementos de uma reflexão. São Carlos: EdUFSCar, 2009.

TARDIF, M. Saberes docentes e formação profissional. Petrópolis: Vozes, 2011.

Recebido: 20/12/2015

Received: 12/20/2015

Aprovado: 20/02/2016

Approved: 02/20/2016 